\title{
APPLYING BIM TO BUILT HERITAGE WITH COMPLEX SHAPES: THE ICE HOUSE OF FILARETE'S OSPEDALE MAGGIORE IN MILAN, ITALY
}

\author{
D. Oreni ${ }^{\mathrm{a}}$, G. Karimi ${ }^{\mathrm{b}}$, L. Barazzetti ${ }^{\mathrm{a}}$ \\ ${ }^{a}$ Politecnico di Milano, Department of architecture, built environment and construction engineering (ABC) \\ Via Ponzio 31, 20133 Milano, Italy \\ (daniela.oreni, luigi.barazzetti)@polimi.it \\ ${ }^{\mathrm{b}}$ Carleton University, Carleton Immersive Media Studio \\ 1125 Colonel by Drive, Ottawa, ON, K1S5B6 - golnazkarimi@cmail.carleton.ca
}

KEYWORDS: Building Information Model (BIM), laser scanning, photogrammetry, documentation, conservation, cultural heritage

\begin{abstract}
:
This paper presents the development of a BIM model for a stratified historic structure characterized by a complex geometry: Filarete's Ospedale Maggiore ice house, one of the few remaining historic ice houses in Milan (Fig. 1). Filarete, a well-known Renaissance architect and theorist, planned the hospital in the $15^{\text {th }}$ century, but the ice house was built two centuries later with a double-storey irregular octagonal brick structure, half under and half above ground, that enclosed another circular structure called the ice room. The purpose of the double-walled structure was to store ice in the middle and store and preserve perishable food and medicine at the outer side of the ice room. During World War II, major portions of the hospital and the above-ground section of the ice house was bombed and heavily damaged. Later, in 1962, the hospital was restored and rehabilitated into a university, with the plan to conceal the ice house's remaining structure in the courtyard, which ultimately was excavated and incorporated into a new library for the university.

A team of engineers, architects, and students from Politecnico di Milano and Carleton University conducted two heritage recording surveys in 2015 and 2016 to fully document the existing condition of the ice house, resulting in an inclusive laser scanner and photogrammetric point cloud dataset. The point cloud data was consolidated and imported into two leading parametric modelling software, Autodesk Revit ${ }^{\odot}$ and Graphisoft ArchiCAD ${ }^{\odot}$, with the goal to develop two BIMs in parallel in order to study and compare the software BIM workflow, parametric capabilities, attributes to capture the complex geometry with high accuracy, and the duration for parametric modelling. The comparison study of the two software revealed their workflow limitations, leading to integration of the BIM generative process with other pure modelling software such as Rhinoceros ${ }^{\circledR}$. The integrative BIM process led to the production of a comprehensive BIM model that documented related historic data and the existing physical state of the ice house, to be used as a baseline for preventive maintenance, monitoring, and future conservation projects.
\end{abstract}
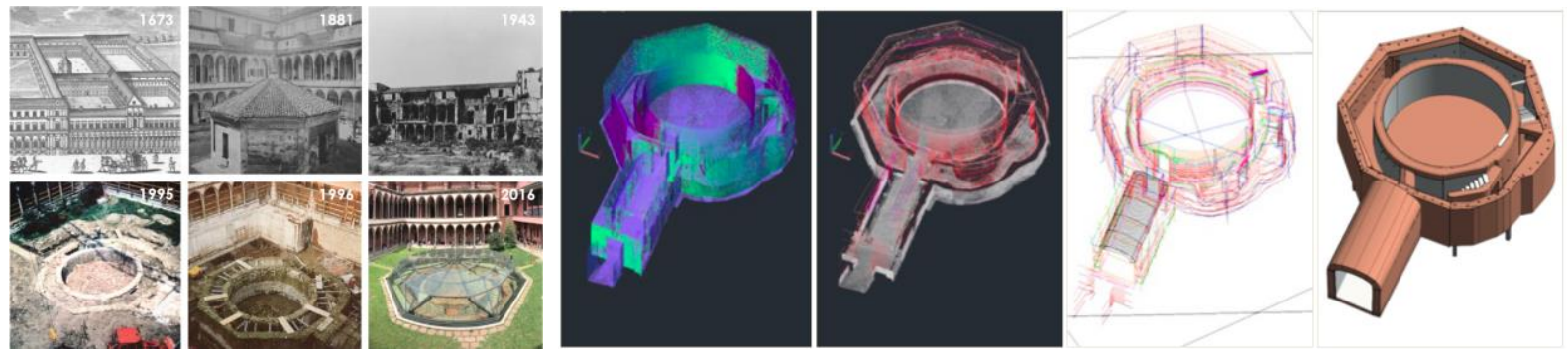

Fig. 1. The ice house of Filarete's Ospedale Maggiore today and in the past (left); an overview of the workflow for Building Information Modelling for built environments with complex forms (right).

\section{INTRODUCTION}

Today, there are numerous digital tools available in the fields of cultural heritage and built environment to generate Building Information Models (BIMs), i.e. advanced models incorporating the information required to support maintenance, conservation and planning activities. BIM has a remarkable potential to help architects, conservators, engineers, restorers, and constructors during the lifecycle of a building. The use of BIM for public buildings is becoming common in many countries (e.g. Australia, Canada, United States and Great Britain). In Italy, in the recent "Public Works Contracts" D.L. 50/2016), it stated and evaluated the use of "digital modelling tools for the buildings and the infrastructure" as an added value for the project development. Moreover, the Italian regulation UNI 11337 on "Digital management of building information processes" recommended to use three families of digital BIM objects, with relative Level of Detail (LOD), Level of Geometry (LOG), and Level of Information (LOI) for new buildings, historical buildings, environment, and infrastructures models. The growing interest in BIM model and process is also confirmed by the development of numerous commercial software (e.g. Revit, ArchiCAD, Vectorworks, Bentley Systems, Allplan, Tekla, SketchUP BIM and RIB iTWO) that take into consideration the different requirements of specialists, such as architects, engineers, designers, planners, construction and facility managers, involved in the construction process 
(Logothetis, 2015). However, BIM processes are mainly used for new constructions with simple and regular geometry. Predefined libraries allow operators to generate reliable models by assembling basic objects (e.g. walls, ceilings, windows, doors, etc.) with known material properties.

BIM is also used for documentation, archiving and management of the built heritage. Consequently, it is first necessary to create a three-dimensional representation of the building, based on object (CRC Construction Innovation, 2009), in order to connect different information. The parametric modelling of an historical building can present some operative difficulties, due to the lack of specific libraries and modelling tools. The complexity in modelling historic constructions having irregular geometry, inhomogeneous materials, variable morphology, alterations and damages, results in several challenges in the digital modelling process. The research has determined that BIM technology has limitations when an accurate representation of a complex historic building is required, especially for the accurate reconstruction of the complex geometries (Italian LOG $\mathrm{G}$ and F - UNI 11337-4), so that the user has to find alternative solutions (stratagems) or simplify the model to overcome the software limitations.

The HBIM (Historical Building Information Modelling) approach is based on the belief that it is necessary to start from surveying data, mainly laser scanners and photogrammetric, to model parametric objects of complex and unique buildings by evaluating, on a case-by-case basis, the possibility of using existing libraries or implementing them (Garagnini, 2015) (Brumana, 2016).

In the technical literature, some examples of complete HBIM of historic buildings were discussed in Murphy et al. (2009; 2013), Fai et al., 2011; Brumana et al. (2013); Baik et al. (2014); Fai et al. (2013), Fai and Rafeiro (2014); Oreni et al. (2012; 2014); Scianna et al. (2014); Barazzetti et al. (2015); Dore et al. (2015); Fassi et al. (2011; 2015), Quattrini et al. (2015), Biagini (2016). The analysis of complex shapes was a common major challenge for which different stratagems (such as implementation of new algorithms for object generation, creation of new families, or excessive simplification) were exploited, having comparable time and cost issues. It is important to underline that the use of a commercial BIM package is mandatory to fulfil basic BIM requirements, avoiding traditional 3D models generated in pure modelling packages (such as Maya, Rhinoceros, and 3D Studio Max) that do not respect BIM requirements because of a lack of parametric modelling tools, spatial relationships and attributes. The paper presents the research in developing the BIM for a multilayered and stratified building, characterized by complex elements: the remains of one of the last historic ice houses in Milan. The laser scanner point cloud and digital photogrammetry data were processed, making a decimation in accordance with the 1:50 scale of representation, in order to obtain geometric modelling of each element, using a semantic component abstraction and a typology identification of the elements.

\section{THE WORK CONCERNING THE ICE HOUSE OF OSPEDALE MAGGIORE}

\subsection{Historical information}

Filarete's Ospedale Maggiore, also called Cà Granda, the "Big House of the Milanese", was the largest hospital of Milan from the $15^{\text {th }}$ to $20^{\text {th }}$ century. The hospital was planned by Filarete (Antonio Averlino, 1400-1469), the well-known Florentine Renaissance architect and theorist, which planned the hospital near the existing canal and started the construction in 1460 . Based on historic information, the existence of the ice house first appeared in 1638 in the middle of the hospital's south-east courtyard designed by Filarete. The ice house building, comprised of a double-storey irregular octagonal brick structure, half under and half above ground, which enclosed another circular structure called the ice room. The purpose of the double-walled structure was to store ice in the center and stock and preserve perishable food and medicine (Vaglienti, 2014) at the outer corridor of the ice room. The walls were also equipped with a series of pipes and channels to allow the warm air and humidity to escape the interior and to keep the ice house cool. The ice house was also connected to the Canal directly through an interior vaulted corridor to transfer ice blocks from the boats to the ice room (Fig. 2. right).
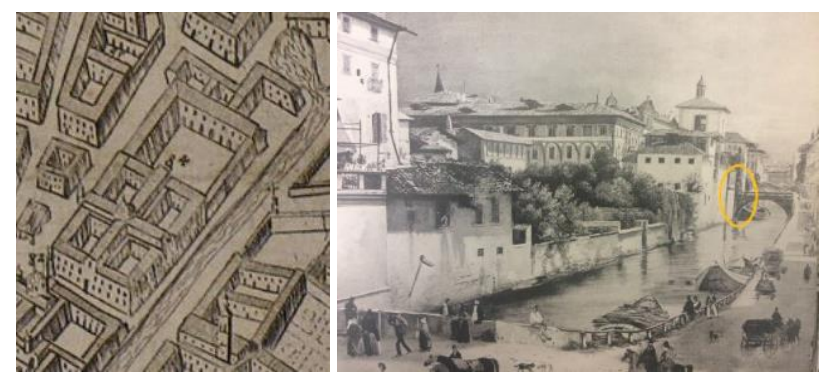

Fig. 2. "La Gran Città di Milano", GioBatta Bonacina, 1699 (left); a $19^{\text {th }}$ century painting of the canal adjacent to the hospital, the yellow circle indicates the entry from the canal (right).

The hospital was heavily bombed during World War II between the $13^{\text {th }}$ and $16^{\text {th }}$ of August, 1943, resulting in the destruction of the courtyards and parts of the lateral cloisters. Particularly, the majority of destruction occurred at the ice house courtyard and the upper part of the ice house's octagonal structure. Two decades after the destruction, in 1962, Liliana Grassi, the conservation architect involved in the restoration project, proposed to cover the underground remaining walls of the ice house with earth and to remove the minor walls leftover from the courtyard at ground level (Grassi, 1972).

The buildings of the ancient hospital were rehabilitated into Statale University starting from 1958 (Franchini, 1995). In 1995, after an archeological campaign (Sena Chiesa, 1998), the ice house structure was excavated and incorporated in a new library for the university built in the basement level of the courtyard; after the completion of the excavation, the underground remaining parts of the ice house were covered with a new glass roof to mark the historic structure. Today, the remaining portions of the ice house are only accessible from the library in the basement and are often closed to visitors due to lack of a program for the restored structure.

Today the existing brick structure of the ice house forms a complex geometry, due to its original construction, the damages from the war, the archaeological excavation, and its final restoration. The maximum extension of the octagonal building measures about $11.5 \mathrm{~m}$, the internal ice room has a diameter of about $7.30 \mathrm{~m}$ and the remaining basement structures are $3.40 \mathrm{~m}$ height. 

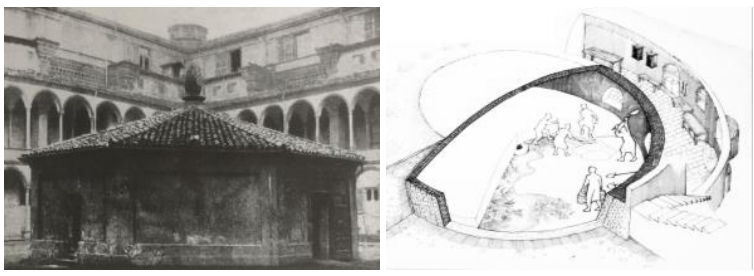

Fig. 3. Ospedale Maggiore's ice house before destruction (left); and a sketch of a typical ice house with double-walled structure (right).

\subsection{Geometrical and photogrammetric documentation}

Two heritage recording campaigns were carried out in 2015 and 2016 by a team of engineers, architects, and students from Politecnico di Milano and Carleton University. The teams performed a series of geometric-constructive analyses of the building and its elements with the goal of evaluating the state of conservation of the structures.

The surveys were conducted with photogrammetric and laser scanning techniques. A set of laser scans was acquired with a Faro Focus 3D (Fig. 4), that were registered using spherical and chess board targets placed on the interior and exterior of the ice house, along the narrow corridor and on the external shell. The final precision of conducted scan registration was approximately $\pm 2 \mathrm{~mm}$.

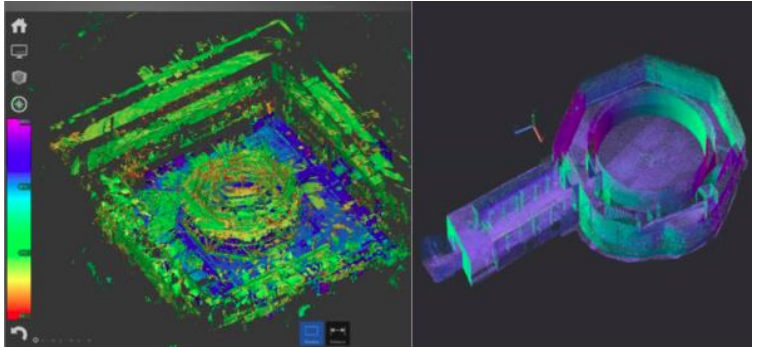

Fig. 4. A visualization of the whole laser point cloud dataset after registration (left); and a detail of the ice house only, after cleaning the point cloud in Autodesk Recap (right).

The laser scanning survey was integrated with a set of images acquired by a Nikon D700 digital camera. The aim was to generate digital orthophotos along the narrow corridor, so that the texture of the brick wall could be visually inspected both on and off site. The height of the wall (about $4 \mathrm{~m}$ ) and the limited space for data acquisition (the corridor was about $1 \mathrm{~m}$ wide) required the use of a $16 \mathrm{~mm}$ fisheye lens, which allowed for significantly less number of images. Images were then photogrammetrically processed with Agisoft PhotoScan software, in which the fisheye camera model was set. The camera and lens were calibrated beforehand using the markerless approach proposed in Barazzetti et al. (2011). This method avoided the estimation of camera parameters during the reconstruction of the object and it provided a more reliable 3D model, from which a set of orthophoto was extracted (Fig. 5). Although the entire wall was visible in a single image strip, more strips (usually 2 or 3 ) were required to avoid the use of the full image, which resulted in a strong distortion and a low quality of the orthophoto for areas close to the image edges.

Processing of metric data allowed to geometrically represent the building, using horizontal and vertical sections, textured with orthophotos.

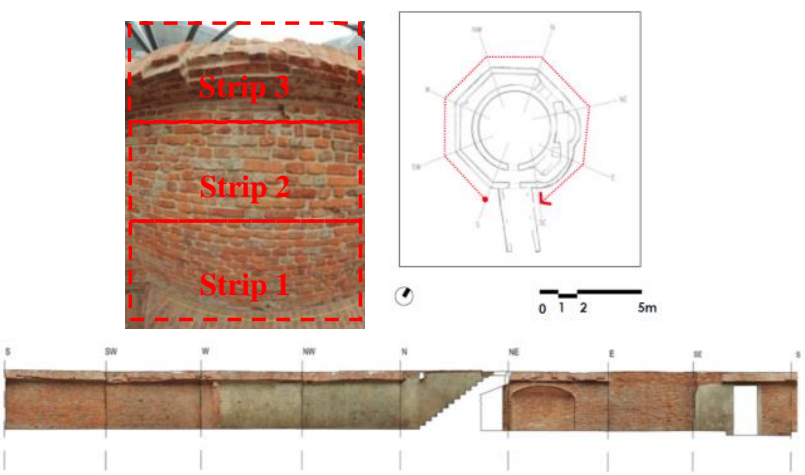

Fig. 5. Example of image acquired with the fisheye lens (topleft); the line along which orthphotos were generated (topright); and final orthophoto of the narrow corridor developed along a stright line (bottom).

\subsection{Parametric modelling process: from classification of building elements to 3D modelling}

A laser scanner and photogrammetric point cloud dataset can capture complex shapes of historic structures. The point clouds containing complex geometries can be imported to BIM software for visualization, documentation, and modelling purposes. As mentioned previously, regular objects with simple geometries can be modelled with the available families of BIM packages mainly designed for new construction assemblies. These predefined families of objects make the BIM modelling for an irregular structure a rather time-consuming and difficult process. The steps that are involved in modelling a complex shape in a BIM software are different and more extensive compared to a typical process of modelling a new assembly. The BIM family of objects and parametric attributes cannot be applied directly to a complex geometry captured by laser scanner and photogrammetric point clouds. The software limitations can force the user to simplify the complex architectural elements during the modelling process, resulting in defective BIM models for documentation, rehabilitation, and conservation projects. This section explains alternative solutions to overcome the limitations of the BIM software for parametric modelling of the ice house's complex form. The laser scanner and photogrammetric point cloud data were imported into two leading parametric modelling software, Autodesk Revit $\odot$ and Graphisoft ArchiCAD $\odot$. This software was used in parallel to produce two individual BIMs of the ice house with the goal to capture the irregularities of the structure with a high metric accuracy of 1:50. Additionally, this case study compares these two leading software to find an efficient parametric modelling process for the ice house and for other similar historic structures with irregular geometries.

Prior to modelling, an inventory of various architectural elements of the ice house was identified (Fig. 6). This inventory includes structural components such as walls, vaults, arches, lintels, floor, stairs, and other utilitarian elements including clay pipes and built-in channels for evaporative cooling, metal fittings to hang stored materials, and voids in the masonry walls to provide storage spaces for food and medicine. The classification of various building elements helps the user to establish the BIM with a comprehensive understanding of the individual elements and their functions, and to establish consistent benchmarks for both Revit and ArchiCAD models and their parametric components. 
Walls
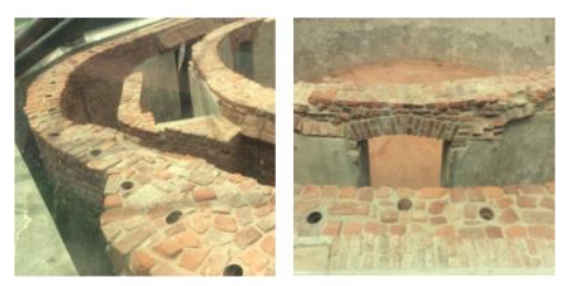

Vaults

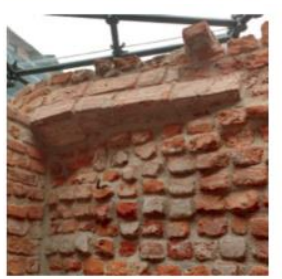

Pipes for evaporative cooling

Arches and lintels
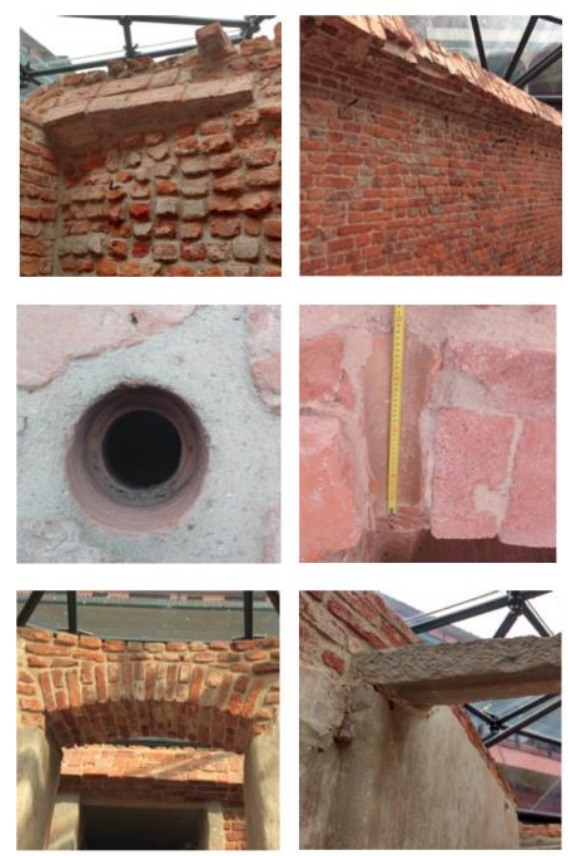

Floors
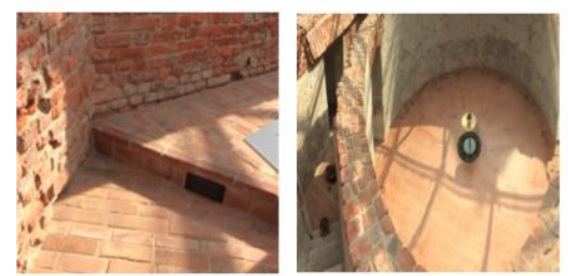

Stairs
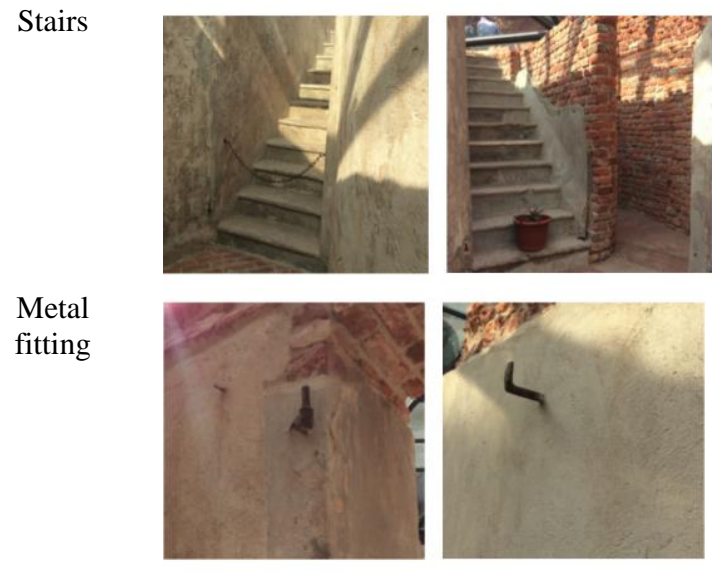

Voids
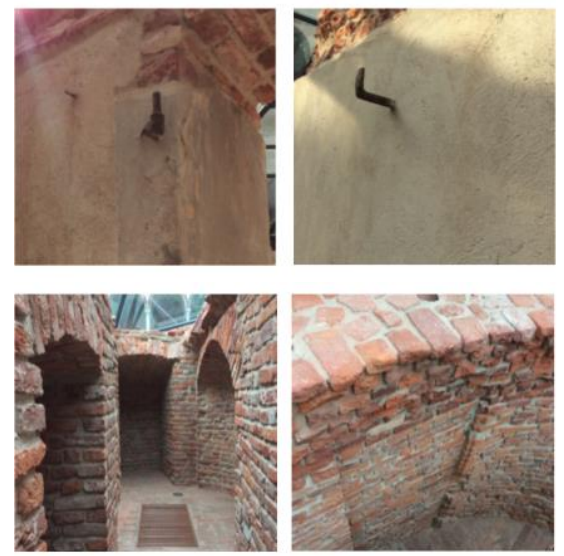
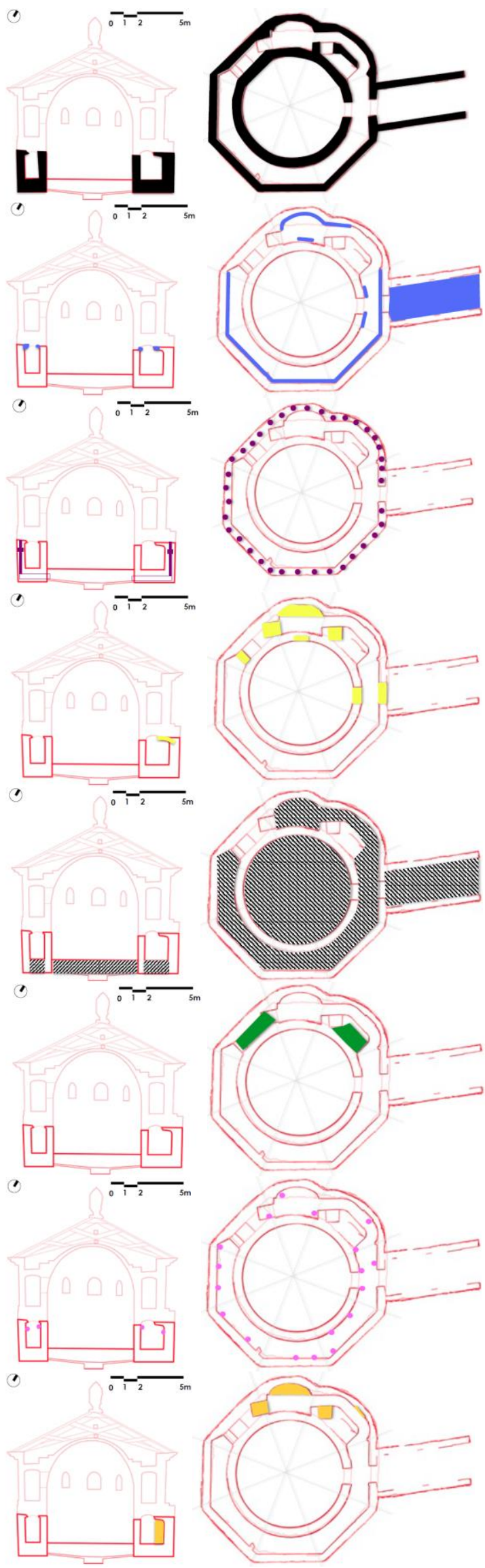

Fig. 6. The different elements of the ice house, classified in different families and modelled using BIM technology. 


\subsection{Autodesk Revit $^{\oplus}$ parametric modelling workflow}

To create a parametric model for the complex geometry of the ice house, the laser scanner point cloud was imported into Autodesk AutoCAD ${ }^{\odot}$ and cut by several horizontal planes at every $350 \mathrm{~mm}$, then the point cloud was traced at every section to extract an accurate outline of the ice house at various heights (Fig. 7). The same exercise was applied to the point cloud with vertical sections at different diagonal coordinates to obtain an accurate profile of the vaults, voids, and stairs. The tracing of all horizontal and vertical sections of the point cloud generated a network of polylines that captured an accurate representation of the ice house's irregular walls, vaults, floors, voids, etc.

To transfer the network of polylines into 3D surfaces, first the produced building components' inventory was applied to order the polylines into different layers. Then the 'Spline' tool was used to connect the polylines and produce a network of curves to be transferred into a 3D surface by AutoCAD 3D modelling tool 'NURBS' surface. To convert the 3D surfaces into parametric objects, each 3D surface was imported into Autodesk Revit as a DWG or SAT file, and was modified with 'Wall by Face' tool to adopt thickness, height, material property, and other desired values (Fig. 8). Similarly, particular shapes such as irregular voids and openings in the solid forms such as walls and vaults were modelled using 'Void' tool by subtracting the accurate negative shapes imported from the polylines network traced from the point cloud data.

However, the described processes do not always work, and the import/export procedures between AutoCAD and Revit can be faulty. For instance, the complex network of the polylines cannot be transferred into a 3D surface at times or else the imported 3D surfaces from CAD to Revit cannot receive the parametric attributes and required material properties.
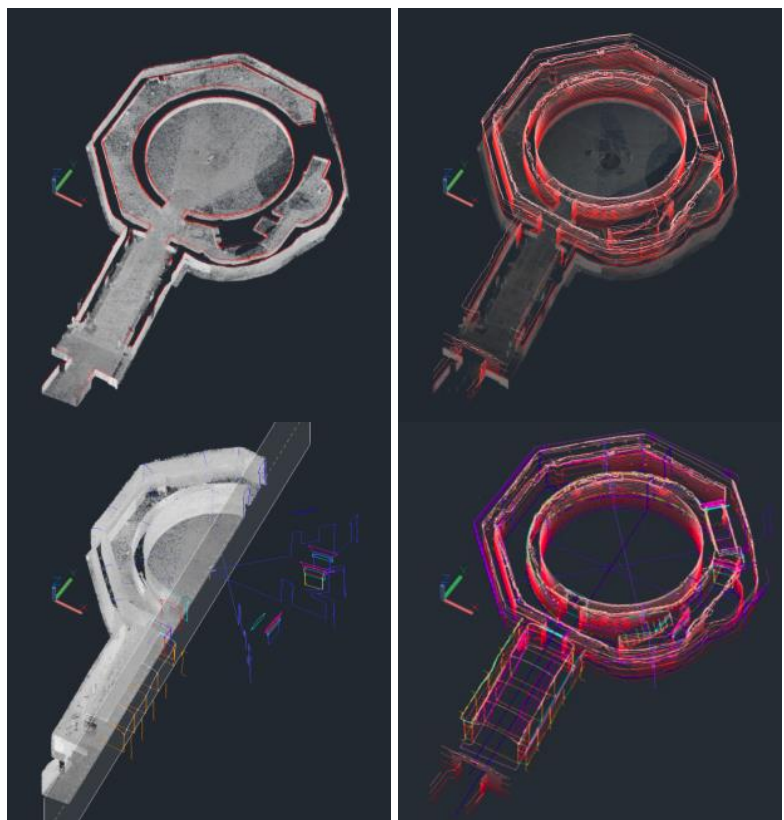

Fig. 7. The complexity of geometry required tracing from point clouds at different horizontal and vertical planes.

Therefore, an alternative solution was executed to overcome the software limitations. The polylines produced by CAD were exported as a DWG file into the pure modelling software Rhinoceros $^{\oplus}$. This software allowed the transformation of all complex surfaces into NURBS surfaces, later imported back into Revit for parametric modelling.
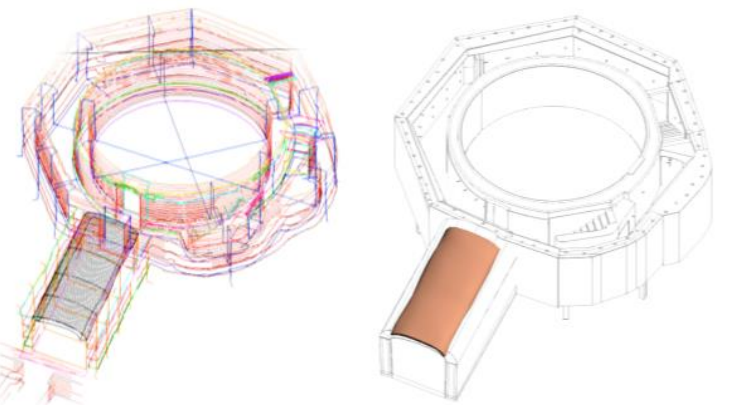

Fig. 8. The process of converting a 3D surafce into a parametric object with specific properties.

\subsection{Graphisoft ArchiCAD $^{\odot}$ parametric modelling workflow}

In parallel, the same exercise was completed in Graphisoft ArchiCAD $^{\odot}$ version 19 . The point cloud data was directly imported into ArchiCAD BIM workflow. A similar process of sectioning the point cloud to extract the accurate outline of the model was repeated. In this case, only vertical sections were cut with distances of $500 \mathrm{~mm}$ throughout the centre point of the point cloud. The profiles of the walls, vaults, arches and lintels at different locations were traced, referenced and saved as a custom component profile for various parts of the structure using the 'Complex Profile' tool (Fig. 9). The software allows these custom profiles to be converted to a parametric object that can be modified and accept various material and physical properties. After 2D tracing of cut profiles and converting them into parametric profiles, the components were drawn in the plan view following the outline of the point cloud and placing the parametric profiles in their proper positions. However, it is not practical and efficient to follow this step for every part of the point cloud and for every component of the structure. The complex profiles caused the parametric model to be adversely segmented with various sectional profiles, leading to simplification of the overall complexity and finding an average profile based on various sections. This issue forced the user to prioritize the accurate modelling of the major components such as the walls and vaults, and simplify the geometry and/or model other components such as floors, stairs, and metal fittings with the predefined object library of the software resulting in lower accuracy of the forms.

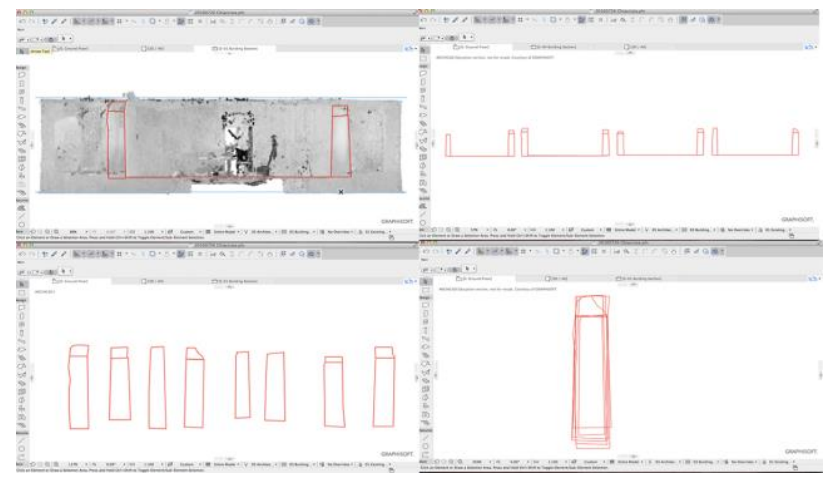

Fig. 9. The process of tracing the point cloud data profiles and creating the custom complex profiles for parametric wall components. 


\subsection{Comparison of Autodesk Revit $^{\odot}$ and Graphisoft} ArchiCAD $^{\odot}$ parametric modelling workflows

The comparison of the studied parametric modelling tools revealed their workflow limitations and advantages (Table 1). The initial step of the parametric modelling workflow and the import of point cloud data involved less steps in ArchiCAD in comparison to Revit. The survey dataset was directly imported and modelled from in ArchiCAD without switching back and forth to other software. This resulted in a shorter timeframe for the overall modelling process. Conversely, the process of importing point cloud data to parametric modelling in Revit is a longer process and requires multiple steps and file transfers from AutoCAD to Revit, or AutoCAD to Rhino and then Revit. In order to enhance the BIM workflow and to facilitate accurate parametric modelling of complex shapes, Revit requires integrating the BIM generative process with other pure modelling software, resulting in a longer and more timeconsuming workflow. ArchiCAD software allows the user to skip the pure modelling step, and to design native complex parametric digital models by applying parametric attributes to complex custom profiles resulted from tracing the point cloud. However, the produced parametric model can be adversely segmented, forcing the user to simplify the geometry and consequently leading to a production of a less accurate model.

\begin{tabular}{ll|l} 
& Autodesk Revit & Graphisoft ArchiCAD \\
\hline $\begin{array}{l}\text { Usability of } \\
\text { point cloud } \\
\text { dataset }\end{array}$ & $\begin{array}{l}\text { Can be directly } \\
\text { imported but } \\
\text { requires other } \\
\text { software to translate } \\
\text { to 2D drawings }\end{array}$ & $\begin{array}{l}\text { Can be directly } \\
\text { imported and converted } \\
\text { to 2D drawings }\end{array}$ \\
\hline $\begin{array}{l}\text { Integration } \\
\text { of other } \\
\text { software }\end{array}$ & $\begin{array}{l}\text { Can involve other } \\
\text { pure modelling } \\
\text { software to achieve } \\
\text { accurate results and } \\
\text { to overcome the } \\
\text { software limitations }\end{array}$ & $\begin{array}{l}\text { No need to integrate } \\
\text { with other software, a } \\
\text { native model can be } \\
\text { achieved with available } \\
\text { complex profile tool }\end{array}$ \\
\hline $\begin{array}{l}\text { Accuracy } \\
\text { High level of } \\
\text { accuracy can be } \\
\text { achieved by } \\
\text { integration of other } \\
\text { pure modelling } \\
\text { software }\end{array}$ & $\begin{array}{l}\text { High level of accuracy } \\
\text { can be achieved, but } \\
\text { the model will be } \\
\text { adversely segmented }\end{array}$ \\
\hline $\begin{array}{l}\text { Number of } \\
\text { steps and } \\
\text { speed of } \\
\text { parametric } \\
\text { modelling }\end{array}$ & $\begin{array}{l}\text { Involves many steps } \\
\text { and much time to } \\
\text { achieve a parametric } \\
\text { model for a } \\
\text { complex shape }\end{array}$ & $\begin{array}{l}\text { Requires fewer steps } \\
\text { and has a relatively } \\
\text { quick parametric } \\
\text { modelling process, but } \\
\text { there is an issue with } \\
\text { segmentation of the } \\
\text { components }\end{array}$ \\
\hline $\begin{array}{l}\text { Overall } \\
\text { workflow }\end{array}$ & $\begin{array}{l}\text { Can achieve } \\
\text { relatively accurate } \\
\text { complex geometries } \\
\text { with parametric } \\
\text { attributes, but the } \\
\text { process is long and } \\
\text { requires integration } \\
\text { of other software }\end{array}$ & $\begin{array}{l}\text { Can achieve parametric } \\
\text { models for complex } \\
\text { shapes with a few steps, } \\
\text { but the workflow forces } \\
\text { the user to simplify } \\
\text { some forms due to } \\
\text { segmentation of the } \\
\text { model }\end{array}$ \\
\hline & & \\
\hline
\end{tabular}

Table. 1. Comparison of BIM workflow for parametric modelling of complex geometris in Revit and ArchiCAD.

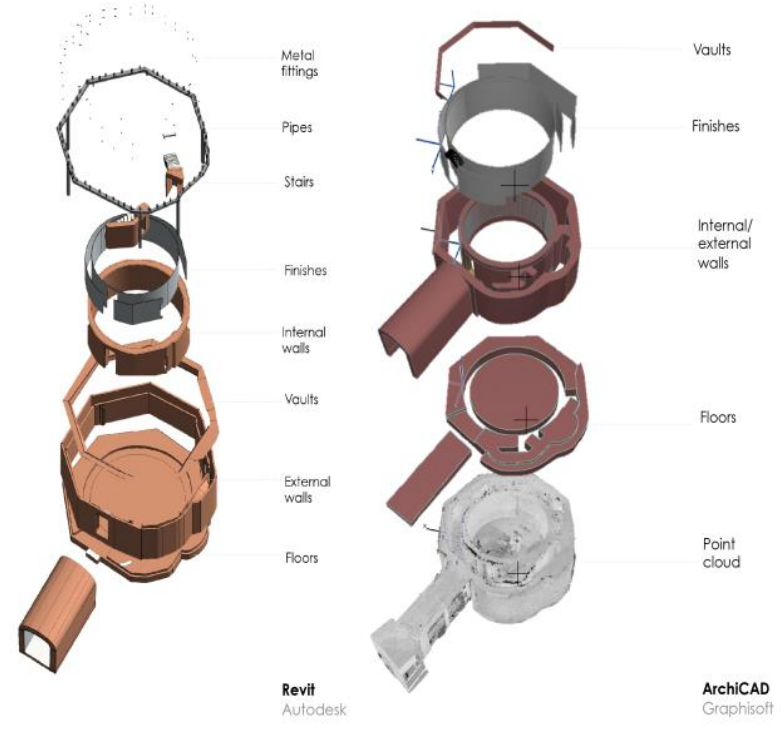

Fig. 10. Exploded view of Revit BIM (left); and ArchiCAD BIM (right).

\subsection{BIM in the cloud for conservation and dissemination project}

An approach for analysis of historic buildings via BIM can be intended as a collaborative solution for all the experts involved in the project such as architects, engineers, constructors, etc. Cloud solutions provide the opportunity to connect multiple operators, which can simultaneously access the latest version of the project, avoiding different project versions with possible changes or modifications. The key idea is a single version of the model that can be remotely accessed.

On the other hand, the complete use of BIM through cloud services still has a limited use in practical applications, as the number of cloud-based BIM systems has rapidly increased (some existing platforms are Autodesk 360, BIM9, BIMServer, BIMx, etc.).

In this work, Autodesk ${ }^{\circledR} 360$ (A360) was used to generate a cloud-based version of the ice house (Fig. 11). Per the description available on the Autodesk website, A360 is "a cloud-based platform that gives you access to storage, a collaboration workspace, and cloud services to help you dramatically improve the way you design, visualize, simulate, and share your work with others anytime, anywhere". Some tools are available for reviewing and navigating the ice room through intuitive touch-based navigation (zoom, pan, rotate) as well as tools for annotation, markup, and comment. Furthermore, this platform is not just intended for visualizing the geometry of a 3D model, but object properties (level, type, category, material, etc.) are accessible and can be viewed by selecting different components. 


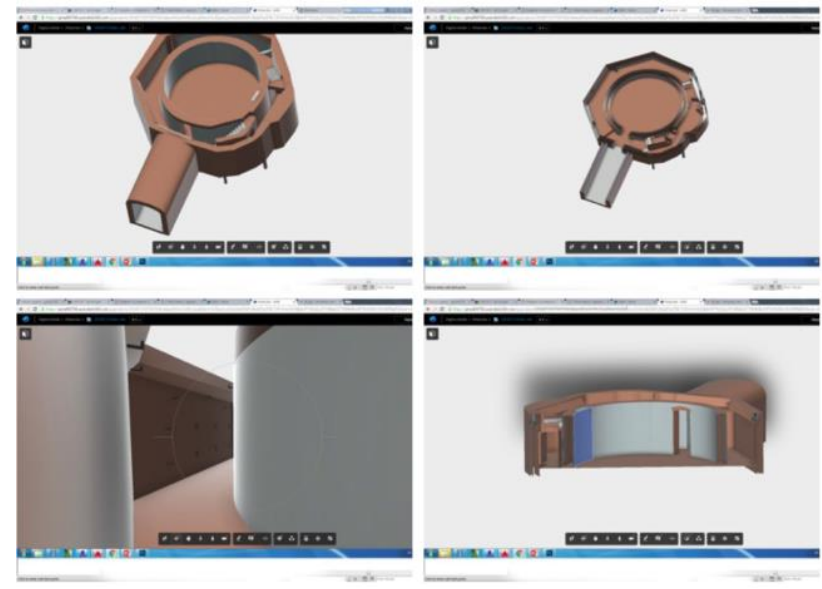

Fig. 11. The cloud-based model of the ice house in A360.

\section{CONCLUSION}

The BIM process led to the production of two comprehensive BIMs that enabled the integration of documented related historic data and the existing physical state of the ice house to be used as a baseline for preventive maintenance, monitoring, future conservation, new cover planning, and dissemination projects.

Not only did the work require an accurate and detailed metric documentation through photogrammetry and laser scanning, but also thorough historic research, interpreting the logic of construction (how the ice room was built), material analyses, previous interventions and modifications, among other fundamental aspects. The approach used to generate the BIM was mainly manual, starting from the identification of constructive elements and their digitalization through curves, surfaces, and BIM parametric objects. The BIM workflow of the two leading parametric modelling software shows that the BIM application for historic structures with complex shapes is a manual process that should be studied on a case by case basis in order to perform an efficient and accurate modelling process for the ice house and for other similar historic structures with irregular geometries.

The comparison of the studied parametric modelling tools revealed their workflow limitations and advantages. The leading parametric software in today's 3D modelling industry Autodesk Revit $^{\odot}$ can achieve relatively accurate complex geometries with parametric attributes, but the process is long and requires integration of other pure modelling software $\mathrm{R} /$ hinoceros $^{\odot}$. The other prominent BIM software Graphisoft $\operatorname{ArchiCAD}^{\odot}$ proved a more efficient workflow process to achieve a parametric model for complex shapes, but segmentation of the model and the software limitations force the user to simplify the true geometry. The complexity of the ice house geometry combined with today's technical limitations of BIM software revealed that historic BIM (HBIM) still remains an open field of research when accurate reconstructions are necessary.

\section{ACKNOWLEDGEMENTS}

This work has been developed under the framework of New Paradigms/New Tools for Heritage Conservation in Canada, a project funded through the Social Sciences and Humanities Research Council of Canada (SSHRC).

We would like to thank the Università degli Studi di Milano and architect Rebecca Fant for providing access to the building.
This work has been supported by the GAMHer project: Geomatics Data Acquisition and Management for Landscape and Built Heritage in a European Perspective, PRIN, Progetti di Ricerca di Rilevante Interesse Nazionale - Bando 2015, Prot. 2015HJLS7E.

\section{REFERENCES}

BAIK, A. ALITANY, A., BOEHM, J. and ROBSON, S., 2014. Jeddah historical building information modelling "JHBIM" object library. ISPRS Annals of Photogrammetry, Remote Sensing and Spatial Information Sciences, 2(5): 41-47.

BARAZZETTI, L., MUSSIO, L., REMONDINO, F., SCAIONI, M., 2011. Targetless Camera Calibration. ISPRS International Archives of the Photogrammetry, Remote Sensing and Spatial Information Sciences, Volume XXXVIII-5/W16, pp.335-342.

BARAZZETTI, L., BANFI F., BRUMANA R., GUSMEROLI G., ORENI D., PREVITALI M., RONCORONI F. and SCHIANTARELLI, G., 2015. BIM from laser clouds and finite element analysis: combining structural analysis and geometric complexity. International Archives of Photogrammetry, Remote Sensing and Spatial Information Sciences, Volume 40(5/W4): 345-350. DOI:10.5194/isprsarchives-XL-5-W4-345-2015.

BIAGINI, C., CAPONE, P., DONATO, V., FACCHINI, N., 2016. Towards the BIM implementation for historical building restoration sites. Automation in Construction, 71: 74-86.

BRUMANA, R., ORENI, D., RAIMONDI, A., GEORGOPOULOS, A., and BREGGIANI, A., 2013. From survey to HBIM for documentation, dissemination and management of built heritage: the case study of St. Maria in Scaria d'Intelvi. Digital Heritage International Congress, Marseille, France. Pages 497-504.

BRUMANA, R., CONDOLEO, P., GRIMOLDI, A., LANDI, A.G., 2017. Shape and construction of brick vaults. criteria, methods and tools for a possible catalogue. International Archives of Photogrammetry, Remote Sensing and Spatial Information Sciences, XLII-5-W1: 137-143.

DORE, C., MURPHY, M., MCCARTHY, S., BRECHIN, F., CASIDY, C. and DIRIX, E., 2015. Structural simulations and structural analysis - historic building information model (HBIM). International Archives of Photogrammetry, Remote Sensing and Spatial Information Sciences, 40(5/W4): 351-357.

FAI, S., GRAHAM, K., DUCKWORTH, T., WOOD, N. and ATTAR, R., 2011. Building Information Modelling and heritage documentation. 23rd International CIPA Symposium. 8 pages.

FAI, S., FILIPPI, M., and PALIAGA, S., 2013. Parametric modelling (BIM) for the documentation of vernacular construction methods: a BIM model for the Commissariat Building, Ottawa, Canada. ISPRS Annals of Photogrammetry, Remote Sensing and Spatial Information Sciences, 2(5/W1): 115-120.

FAI, S. and RAFEIRO, J., 2014. Establishing an appropriate level of detail (LoD) for a building information model (BIM) West Block, Parliament Hill, Ottawa, Canada. ISPRS Annals of the Photogrammetry, Remote Sensing and Spatial Information Sciences, 2(5): 123-130. 
FASSI, F., ACHILLE, C. and FREGONESE, L., 2011. Surveying and modelling the main spire of Milan Cathedral using multiple data sources. Photogrammetric Record, 26(136): 462-487.

FRANCHINI, L., 1995. L'Ospedale Maggiore di Milano dedicato all'Annunziata, detto Cà Granda. Ospedali Lombardi del Quattrocento. Fondazione, trasformazioni, restauro. Como: 137-177.

GARAGNINI, S., 2015. Semantic Representation of Accurate Surveys for the Cultural Heritage: BIM Applied to the Existing Domain. 9: 292-309.

GRASSI, L., 1972. Lo "Spedale dei poveri” del Filarete. Storia e restauro. Milano.

LOGOTHETIS, S., DELINASIOU A., STYLIANIDIS, E., 2015. Building information modelling for cultural heritage: a review. ISPRS Annals of the Photogrammetry, Remote Sensing and Spatial Information Sciences, 2(5/W3): 177-183.

MURPHY, M., MCGOVERN, E. and PAVIA, S., 2009. Historic building information modelling (HBIM). Structural Survey, 27(4): 311-327.

MURPHY, M., MCGOVERN, E., and PAVIA, S., 2013. Historic building information modelling - adding intelligence to laser and image based surveys of European classical architecture. ISPRS Journal of Photogrammetry and Remote Sensing, 76: 89-102.

ORENI, D., BRUMANA, R. and CUCA, B., 2012. Towards a methodology for 3D content models. the reconstruction of ancient vaults for maintenance and structural behavior in the logic of BIM management. 18th International Conference on Virtual Systems and Multimedia - Virtual Systems in the Information Society, Milan, Italy. Pages 475-482.

ORENI, D., BRUMANA, R., BANFI, F., BERTOLA, L., BARAZZETTI, L., CUCA., B., PREVITALI, M. and RONCORONI, F., 2014. Beyond crude 3D models: from point clouds to historical building information modelling via NURBS. Lecture Notes in Computer Science, 8740: 166-175.

QUATTRINI, R., MALINVERNI, E.S., CLINI, P., NESPECA, R. and ORLIETTI, E., 2015. From TLS to HBIM: high quality semantically-aware 3D modelling of complex architecture. International Archives of Photogrammetry, Remote Sensing and Spatial Information Sciences, Volume 40(5/W4), 367-374.

SCIANNA A., GRISTINA, S. and PALIAGA S., 2014. Experimental BIM applications in archaeology: a work-flow. Digital Heritage, Progress in Cultural Heritage: Documentation, Preservation, and Protection, Lecture Notes in Computer Science, 8740: 490-498.

SENA CHIESA, G., 1998. Cellae in Hospitali exsistentes. Gli scavi nei cortili della Cà Granda. Milano.

STAMATOPOULOS, C., FRASER, C.S, 2014. Automated Target-Free Network Orientation and Camera Calibration. Int. Arch. Photogramm. Remote Sens. Spat. Inf. Sci. 2014;1: 339_ 346.
UNI 11337-4: 2017. Edilizia e opere di ingegneria civile Gestione digitale dei processi informativi delle costruzioni Parte 4: Evoluzione e sviluppo informativo di modelli, elaborati e oggetti.

VAGLIENTI, F., 2014. La Cà Granda dei milanesi. Interdisciplinary itinerary in the heart of multicultural metropolis. Milano. 